\title{
Single exposure of dopamine DI antagonist prevents and D2 antagonist attenuates methylphenidate effect
}

This article was published in the following Dove Press journal:

Journal of Experimental Pharmacology

20 April 2015

Number of times this article has been viewed

\author{
Catherine M Claussen \\ Lindsey J Witte \\ Nachum Dafny \\ Department of Neurobiology and \\ Anatomy, The University of Texas \\ Health Science Center Medical School \\ at Houston, Houston, TX, USA
}

\begin{abstract}
Methylphenidate (MPD) is a readily prescribed drug for the treatment of attention deficit hyperactivity disorder (ADHD) and moreover is used illicitly by youths for its cognitive-enhancing effects and recreation. MPD exposure in rodents elicits increased locomotor activity. Repetitive MPD exposure leads to further augmentation of their locomotor activity. This behavioral response is referred to as behavioral sensitization. Behavioral sensitization is used as an experimental marker for a drug's ability to elicit dependence. There is evidence that dopamine (DA) is a key player in the acute and chronic MPD effect; however, the role of DA in the effects elicited by MPD is still debated. The objective of this study was to investigate the role of D1 and/or D2 DA receptors in the acute and chronic effect of MPD on locomotor activity. The study lasted for 12 consecutive days. Seven groups of male Sprague Dawley ${ }^{\circledR}$ rats were used. A single D1 or D2 antagonist was given before and after acute and chronic MPD administration. Single injection of D1 DA antagonist was able to significantly attenuate the locomotor activity when given prior to the initial MPD exposure and after repetitive MPD exposure, while the D2 DA antagonist partially attenuated the locomotor activity only when given before the second MPD exposure. The results show the role, at least in part, of the D1 DA receptor in the mechanism of behavioral sensitization, whereas the D2 DA receptor only partially modulates the response to acute and chronic MPD.
\end{abstract}

Keywords: behavior, Ritalin, dopamine anatagonist, behavioral sensitization

\section{Introduction}

Methylphenidate (MPD) is currently the most prescribed psychostimulant drug therapy for children and adults exhibiting symptoms of inattention, hyperactivity, and impulsivity, collectively known as attention deficit hyperactivity disorder (ADHD); ${ }^{1-7}$ ADHD has a high threat of overdiagnosis due to widespread symptoms, with a staggering $8 \%$ of school-aged children identified with the disorder and $36 \%$ of these children undergoing drug treatment. ${ }^{8,9}$ MPD is also widely abused, earning the name "smart drug" as society's obsession for cognitive enhancements grows in the classroom and workplace. ${ }^{10}$ Moreover, little is known about the exact pharmacological actions of the drug, specifically in chronic "healthy" users. ${ }^{11,12}$ The use of psychostimulants as a treatment for ADHD has doubled every 4-7 years for the past few decades, heightening concerns of this drug, while leading ADHD to become one of the most extensively studied pediatric behavioral disorders. ${ }^{9,13-15}$

Repetitive moderate exposure to a psychostimulant, in animals, results in an augmented behavioral response, such as locomotion, to the subsequent administration of the drug, frequently referred to as behavioral sensitization. ${ }^{16-20}$ In comparison, tolerance
Correspondence: Nachum Dafny The University of Texas Health Science Center Medical School at Houston, Department of Neurobiology and Anatomy, 643I Fannin St, MSB 7.208B, Houston, TX 77030, USA

$\mathrm{Tel}+\mathrm{I} 7135005616$

Fax +I 713500062I

Email nachum.dafny@uth.tmc.edu License. The full terms of the License are available at http://creativecommons.org/licenses/by-nc/3.0/. Non-commercial uses of the work are permitted without any further (cc) (i) (8) 2015 Claussen et al. This work is published by Dove Medical Press Limited, and licensed under Creative Commons Attribution - Non Commercial (unported, v3.0) permisson how to request permission may be found at: http://www.dovepress.com/permissions.php 
to the drug is characterized by lowering locomotor activity in response to repetitive MPD exposure compared with the initial response. Eliciting sensitization or tolerance reveals drug-craving and compulsive actions, which are both signs of drug dependency; ${ }^{19,21,22}$ therefore, behavioral sensitization and tolerance are used as experimental markers for studying the potential risks of psychostimulant treatment.

MPD binds to dopamine (DA) transporters, thus preventing the reuptake of DA from the synaptic cleft back to the presynaptic neurons ${ }^{19,23,24}$ and causing DA to remain in the synaptic cleft for longer periods of time. Moreover, the DA neurotransmitter system has been linked with drug reward properties, with previous work providing evidence that the D1 and/or D2 family of DA receptors are involved in acute and/or chronic MPD action; ${ }^{19}$ however, the exact role of DA receptors in the acute and/or chronic behavioral effect of MPD exposure need more elucidation. Previous reports state that behavioral sensitization following chronic psychostimulant treatment is due to elevated levels of DA in the synaptic cleft. ${ }^{11,18,25,26}$ Thus, this study used specific competitive, DA D1 and D2 antagonists, SCH-23990 and raclopride, given before and after acute and chronic MPD exposure while recording the animal's subsequent behavior in an open field assay, to determine the role of specific DA receptor participation in the acute and/or chronic effects of MPD treatment on animal locomotor activity.

MPD's chemical structure is similar to amphetamine, while its pharmacological characteristics closely resemble cocaine..$^{12,26,27}$ Moreover, the amphetamine and cocaine studies investigating the role of D1 and D2 DA receptors in eliciting behavioral sensitization were using the D1 and D2 DA-specific antagonists SCH-23390 and raclopride, ${ }^{25}$ respectively. In these works, SCH-23390 D1 DA antagonist treatment prior to chronic exposure prevented the development of cocaine behavioral sensitization using a place preference assay, while the D2 DA antagonist raclopride was not effective, though other studies reported that the D2 DA receptor is involved in psychostimulant sensitization. ${ }^{28,29}$ On the other hand, D2 DA antagonists suppressed both locomotor-stimulating effects and scheduleinduced polydipsia with amphetamine treatment. ${ }^{19,30-32}$ In addition, previous studies using MK-801, valproate, and lithium chloride injections before and after acute and chronic MPD exposure revealed some success at preventing MPD from eliciting behavioral sensitization or tolerance. ${ }^{33-37}$

The objective of the present study was to investigate whether the specific DA D1 and D2 receptor antagonist would modulate, at least in part, the acute and repetitive (chronic) MPD exposure, using an open field behavioral assay.

\section{Methods}

\section{Subjects}

Fifty-six adult, 180-200 g, male Sprague-Dawley ${ }^{\circledR}$ rats were purchased from Harlan (Indianapolis, IN, USA). The animals were allowed 4-5 days of acclimation in the vivarium, with a 12-hour light/dark cycle (lights on 6 am), while the temperature and humidity were kept at a constant $21^{\circ} \mathrm{C} \pm 2{ }^{\circ} \mathrm{C}$ and $37 \%-45 \%$, respectively. The rats were randomly divided into seven groups (Table 1) and individually housed and tested

Table I The experimental protocol

\begin{tabular}{|c|c|c|c|c|c|c|c|}
\hline \multirow[t]{2}{*}{ Group } & \multirow[t]{2}{*}{ EDI } & \multirow{2}{*}{$\begin{array}{l}\text { Acute } \\
\text { ED2 }\end{array}$} & \multicolumn{3}{|l|}{ Induction } & \multicolumn{2}{|c|}{ Expression } \\
\hline & & & ED3 & ED4-7 & ED8- 10 & EDII & EDI 2 \\
\hline I $(n=8)$ & Saline & Saline & Saline & Saline & Washout & Saline & Saline \\
\hline $2(n=8)$ & Saline & $\begin{array}{l}\text { DI antag at } 7 \text { am } \\
\text { MPD at 7:30 am }\end{array}$ & MPD & MPD & Washout & MPD & MPD \\
\hline $3(n=8)$ & Saline & $\begin{array}{l}\text { D2 antag at } 7 \mathrm{am} \\
\text { MPD at 7:30 am }\end{array}$ & MPD & MPD & Washout & MPD & MPD \\
\hline $4(n=8)$ & Saline & MPD & $\begin{array}{l}\text { DI antag at } 7 \mathrm{am} \\
\text { MPD at 7:30 am }\end{array}$ & MPD & Washout & MPD & MPD \\
\hline $5(n=8)$ & Saline & MPD & $\begin{array}{l}\text { D2 antag at } 7 \text { am } \\
\text { MPD at 7:30 am }\end{array}$ & MPD & Washout & MPD & MPD \\
\hline $6(n=8)$ & Saline & MPD & MPD & MPD & Washout & MPD & $\begin{array}{l}\text { DI antag at } 7 \text { am } \\
\text { MPD at } 7: 30 \text { am }\end{array}$ \\
\hline $7(n=8)$ & Saline & MPD & MPD & MPD & Washout & MPD & $\begin{array}{l}\text { D2 antag at } 7 \text { am } \\
\text { MPD at 7:30 am }\end{array}$ \\
\hline
\end{tabular}

Notes: At EDI, all animals were injected with saline. At ED2-7, the animals were given either saline (control group) or MPD $2.5 \mathrm{mg} / \mathrm{kg}$ IP. ED8-10 were washout days, with no injections. At ED I I and ED I2, saline or MPD rechallenge was administered. The experiment lasted for I 2 days, with seven groups of animals used (each $n=8$ ). Group I was treated with the saline control; group 2 received a DI DA antagonist at ED2, prior to the initial MPD exposure; group 3 received a D2 antagonist at ED2, prior to the initial MPD exposure; group 4 received a DI antagonist at ED3, prior to the second MPD exposure; group 5 received a D2 antagonist at ED3, prior to the second MPD exposure; group 6 received a DI antagonist at EDI2, prior to the last MPD rechallenge; group 7 received a D2 antagonist at EDI2, prior to the last MPD rechallenge.

Abbreviations: antag, antagonist; DA, dopamine; ED, experimental day; IP, intraperitoneal route; MPD, methylphenidate. 
in home cages for the duration of the experimental protocol; the animals had access to standard laboratory chow and water ad libitum, except during the behavioral recordings. At experimental day (ED)1, the animals weighed 200-220 g. All experiments were approved by the University of Texas Health Science Center Animal Welfare Committee and carried out in accordance with the National Institute of Health Guide for Care and Use of Laboratory Animals.

\section{Apparatus}

The open field assay was used to record the animals' locomotion activities for 12 consecutive days (Table 1), using the computerized animal activity system (Opto-M3; Columbus Instruments, Columbus, OH, USA). The open field cage was $50 \mathrm{~cm}$ long, $30 \mathrm{~cm}$ wide, with a $16 \times 8$ infrared beam and their sensors positioned $5 \mathrm{~cm}$ above the base of the cage, to prevent bedding signal interruptions. Each animal's movement was captured by breaking the infrared beams. Any interruptions in the infrared beams factored into an activity score, and these cumulative counts were compiled, in 5-minute bins, for a total of 60 minutes after each injection. The software incorporated the locomotor counts into three behavioral indices: total distance (TD) traveled in cm; horizontal activity, capturing the total spontaneous locomotion behavior; and number of stereotypic movements, which measured repetitive episodes of purposeless activity. These three activities measure the overall behavioral effect of a drug. ${ }^{4-7,17,34,35,38-41}$

\section{Drugs}

MPD (Mallinckrodt, St Louis, MO, USA) and DA D1 and D2 receptor antagonists, $\mathrm{R}(+) \mathrm{SCH}-23390$ hydrochloride and $\mathrm{S}(-)$-raclopride (+)-tartrate (Sigma-Aldrich Corp, St Louis, MO, USA), respectively, were used. All injections were made fresh, dissolving the drug in $0.9 \%$ isotonic saline, equalized to $0.8 \mathrm{~mL}$, and injected, via intraperitoneal (IP) route, in the morning. In previous MPD dose-response behavioral experiments ranging from 0.1 to $40.0 \mathrm{mg} / \mathrm{kg}$, it was observed that $2.5 \mathrm{mg} / \mathrm{kg}$ of MPD elicited behavioral sensitization when given in the morning ${ }^{36,41-45}$ therefore, this dosage $(2.5 \mathrm{mg} / \mathrm{kg}$ ) was selected. Previous studies used a range of $0.2-0.5 \mathrm{mg} / \mathrm{kg} \mathrm{SCH}-23390$ selective D1 DA antagonist and $0.3-0.4 \mathrm{mg} / \mathrm{kg}$ raclopride selective D2 DA antagonist, which were effective in modulating the psychostimulant effect on animal behavior and on the prefrontal cortex. ${ }^{19,46}$ Therefore, we chose SCH-23390, $0.4 \mathrm{mg} / \mathrm{kg}$, and D2 DA antagonist raclopride, $0.3 \mathrm{mg} / \mathrm{kg}$, to study the role of the D1 and D2 DA receptors in the effects of acute and chronic MPD exposure on animal behaviors.

\section{Experimental protocol}

In general, after the additional 4-5 days of acclimation, the animals were randomly assigned to groups and to their home cage for an additional 2-3 days. The home cage was utilized as their test cage, and recordings began to obtain baseline activity following $0.8 \mathrm{~mL}$ saline injections $(0.9 \% \mathrm{NaCl})$, at about 7:30 am, for 1 hour. On ED2-7, all animals received injections of either $0.9 \%$ saline (the control group) or $2.5 \mathrm{mg} / \mathrm{kg}$ of MPD (the drug group), and locomotor recordings resumed postinjection for an additional 1 hour (Table 1). Three days (ED8-10) were allotted for washout (ie, no injections); however, behavioral recordings again resumed for 1 hour at about 7:30 am for 60 minutes, at the same time as was done on ED1 to ED7, to determine possible anticipation behavior or withdrawal activity. ${ }^{47,48}$ Rechallenge exposure of MPD, followed by 60-minute recordings occurred on ED11 and ED12, to determine whether sensitization or tolerance was expressed (Table 1). The seven groups described below and in Table 1 differed with respect to when and which specific DA antagonist they received, to determine the role of D1 and D2 DA receptors in the acute and/or chronic effect of MPD.

Group 1 was the saline (control) group; this group was treated with saline at ED1-7 and at ED10-12 (Table 1).

Groups 2 and 3 received their assigned D1 or D2 DA receptor antagonists on ED2 prior to MPD exposure, at about 7 am, and 30 minutes were allotted for behavioral recordings, to determine whether the DA antagonists modulated baseline activity; then the rats received their MPD treatment, followed by 1 -hour recordings (Table 1). These groups were used to assess the effects of DA antagonist on acute MPD effects.

Groups 4 and 5 were treated with saline at ED1 and with MPD at ED2. At ED3, prior to the second MPD exposure, they received their assigned D1 or D2 DA receptor antagonists injection at about 7 am (ED3 induction phase), and recording commenced for 30 minutes, recording was resumed following an MPD injection (ie, the second MPD exposure) and, at 1 hour post-MPD, behavioral recording.

Lastly, groups 6 and 7 were used to study the effect of the DA antagonist on the expression of chronic MPD exposure. These groups ( 6 and 7) received daily MPD exposures at ED2 through ED7 and again at ED11, followed by their assigned D1 or D2 DA receptor antagonists on ED 12, at approximately 7 am; after this, recordings were resumed for 30 minutes, followed by MPD rechallenge exposure, and the recordings were resumed for an additional 1 hour (Table 1). 


\section{Data analysis}

Locomotor activity was collected into 5-minute bins during each recording session (ie, 12 bins in 60 minutes). To determine whether the D1 or D2 DA antagonists significantly modulated the baseline activity or the MPD effects on locomotor activity, an analysis of variance (ANOVA) with post hoc Dunnet multiple comparison tests were used. This analysis determined whether there was a significant difference between the MPD control groups (groups 6 and 7) at ED11 (Table 1) and the groups treated with the D1 or the D2 antagonist at ED2 prior to the initial MPD exposure, ie, groups 2 and 3, as well as groups 4 and 5 . The last comparisons were of groups 6 and 7, at ED12 post-MPD exposure and at ED11 post-MPD (the same group).

The effect of a psychostimulant can be divided into four phases: "acute" phase, showing the initial effect of the drug on MPD-naïve subjects, obtained by comparing the recording at ED2 after initial (acute) MPD to the ED1 recording postsaline; "induction" phase, obtained from the recording during the repetitive MPD exposure; "withdrawal" phase, following cessation of repetitive (chronic) drug exposure, obtained from the recording at ED8-10 (after the six daily MPD exposures); and "expression" phase, obtained from the recording following rechallenge of drug exposure after six daily MPD exposures, 3 days of washout, and MPD exposure at ED11 and/or 12. For this group, the antagonist was given at ED12, prior to the last MPD exposure (Table 1). Applying specific DA antagonists in different phases of MPD exposure in freely behaving animals in an open field assay, we hoped to reveal, at least in part, the role of D1/D2 DA receptors in acute and chronic MPD exposure.

\section{Results}

\section{Control}

\section{Saline control}

To determine if normal daily locomotor activity was modulated by handling or injection, eight animals were treated with saline for the 12 days (group 1) (Table 1). Minor random fluctuations in activity, with nonsignificant changes, were observed over the 12 EDs (Figure 1A). Since no significant deviations occurred between ED2-7 and ED11-12 compared with ED1 activity after saline injection, the activity after saline injection at ED1 was used as a control for the drug effect. Concurrent with previous studies using a similar experimental protocol, any deviations from saline treatment at ED1 was due to drug effects since saline alone had no significant effect on a rat's locomotor activity. ${ }^{4-6,17,34,35,41}$

\section{MPD control}

Sixteen animals received acute and repetitive $2.5 \mathrm{mg} / \mathrm{kg}$ MPD injections prior to DA antagonist exposure, to serve as a control for acute and chronic MPD exposure (groups 6 and 7) (Table 1). The "acute" $2.5 \mathrm{mg} / \mathrm{kg}$ IP MPD elicited a significant $(P<0.007, F=3.5)$ increase in their locomotion (Figure 1B), and a significant further increase was observed in their locomotor activity following repetitive (chronic) MPD activity $(P<0.05, F=5.4)$. The significant increase in locomotion following MPD exposure at ED11 compared with ED2 post-MPD exposure was interpreted as the expression of behavioral sensitization. ${ }^{5,6,17,35,37,39,44,45}$

\section{DI and D2 DA antagonist control}

Figure 1C summarizes the effect of the two DA antagonists (D1 and D2) on locomotor activity of MPD-naïve animals
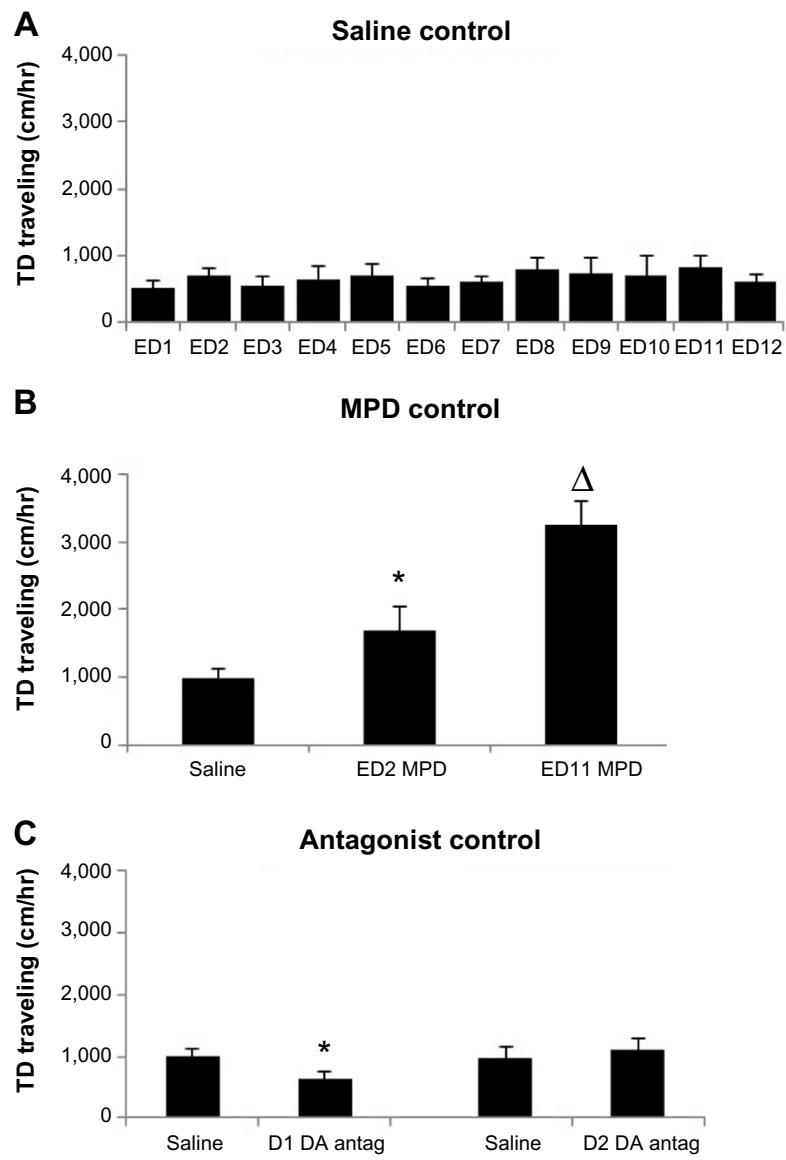

Figure I (A) TD traveling of the saline (control) control group, ie, I (Table I). The histogram shows the average $(n=8)$ TD traveled for the 12 EDs following saline injection and shows that saline injection and animal handling did not affect the TD traveling. (B) TD traveling for the MPD control group. The histogram shows the acute MPD effect (ED2 MPD) and the effect of MPD rechallenge at EDI I. (C) Effect of the DI and D2 DA antagonist on saline (baseline) activity.

Notes: *Significant $(P<0.05)$ difference from saline (control); ${ }^{\Delta}$ significant $(P<0.05)$ difference in locomotor activity at EDI I compared with ED2 (similar observations were obtained for horizontal activity and stereotypic movements).

Abbreviations: DA, dopamine; ED, experimental day; MPD, methylphenidate; TD, total distance. 
(groups 2 and 3). ED2 postantagonist was compared with ED1 (baseline). The SCH-23990 D1 DA-specific antagonist significantly reduced $(P<0.004, F=10.78)$ the animals locomotor activity, while the raclopride D2 DA antagonist failed to modulate the animals' locomotor activity.

\section{The effect of DA antagonist given prior to initial MPD exposure (groups 2 and 3 )}

In groups 2 and 3, the D1 or D2 DA antagonist was given 30 minutes prior to the initial MPD exposure, to investigate whether the DA antagonist by itself had an effect as well as the effect of DA antagonist given before the initial (acute) MPD exposure (Figure 2A and Table 1). We used the ED2 data from groups 6 and 7 as control for MPD. The results showed that $2.5 \mathrm{mg} / \mathrm{kg}$ MPD caused a significant $(P<0.006, F=10.18)$ increase in TD traveling, and the effect of MPD (group 2) given 30 minutes after the D1 DA antagonist showed a significant

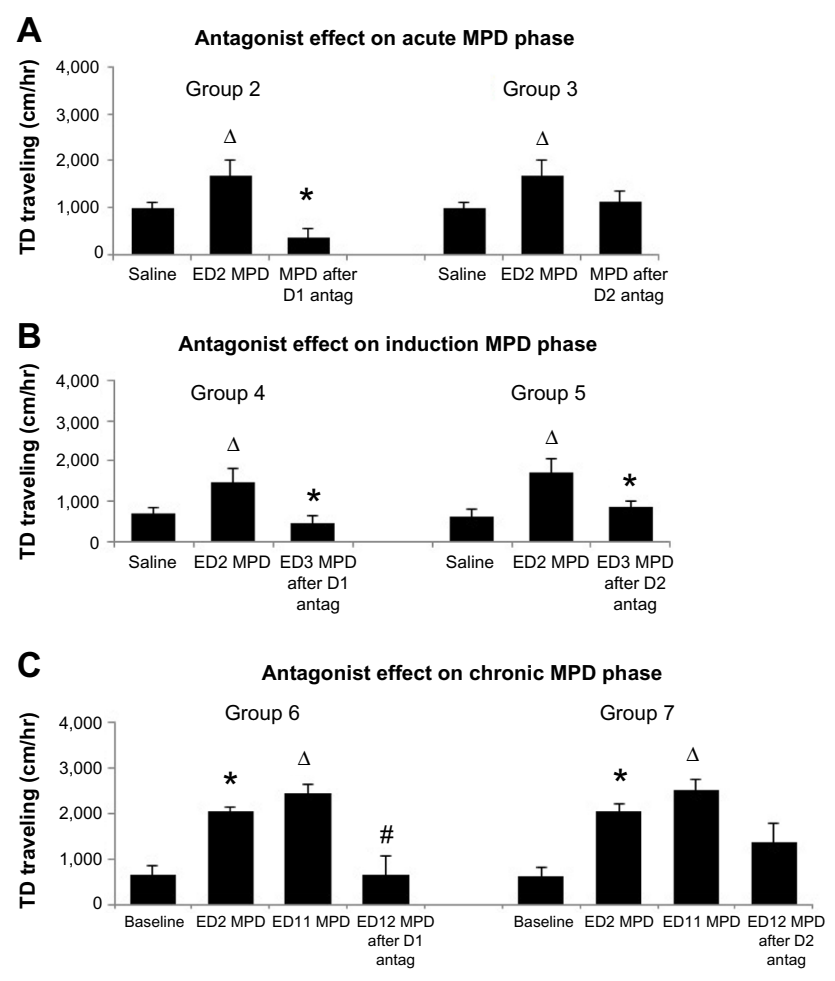

Figure 2 TD traveling, in $\mathrm{cm}$, following (A) the DI and D2 DA antagonist, given prior to the initial (acute) MPD exposure for groups 2 and 3, respectively; (B) DI and D2 DA antagonist, given 30 minutes prior to the second MPD exposure, to groups 4 and 5 respectively, to determine the effect of the DA antagonist on the induction phase of MPD exposure; and (C) DI and D2 antagonist, given to groups 6 and 7 respectively, at EDI2, 30 minutes prior to MPD rechallenge, to determine the effect of the DA antagonist on the chronic effect of MPD exposure.

Notes: *Significant $(P<0.05)$ difference from EDI baseline activity; ${ }^{\Delta}$ significant $(P<0.05)$ difference in locomotor activity at EDI I compared with that at ED2 initial MPD exposure; "significant $(P<0.05)$ difference in the MPD rechallenge activity at EDI 2 following a DI or D2 DA antagonist as compared with that on EDII (similar observations were obtained for horizontal activity and stereotypic movements). Abbreviations: antag, antagonist; DA, dopamine; ED, experimental day; MPD, methylphenidate; TD, total distance.
$(P<0.005, F=9.25)$ decrease in TD traveled compared with the effect of MPD in the control groups (groups 6 and 7). Alternately, the D2 antagonist given 30 minutes prior to the initial MPD exposure did not significantly $(P<0.16, F=2.5)$ modulate the TD traveling response to acute MPD administration, for group 2, when compared with the control groups 6 and 7 or with its own ED1 baseline activity (Figure 2). Similar observations were obtained for the horizontal activity and number of stereotypic movements (not shown).

\section{Effect of DA antagonist on MPD given during the induction phase (groups 4 and 5)}

Animals of groups 4 and 5 (Table 1) were treated with the initial MPD at ED2, followed by D1 (group 4) or D2 (group 5) DA antagonist on ED3, 30 minutes prior to the second MPD exposure. Figure 2B shows that the acute MPD elicited significant $(P<0.005, F=9.85)$ increase in activity, and their locomotor activity following MPD on ED3 preceding the D1 and D2 DA antagonist was significantly reduced $(P<0.01$, $F=7.3$ and $P<0.03, F=5.3$, respectively) for both groups.

\section{Effect of DA antagonist on MPD given in the expression phase (groups 6 and 7)}

The animals of groups 6 and 7 received the D1 or D2 DA antagonists on ED12, 30 minutes prior to the last MPD exposure (Table 1). These animals were exposed to six daily MPD injections (ED2-7) followed by 3 days of washout (ED8-10), and rechallenge with MPD on ED11 to verify whether behavioral sensitization was obtained (Table 1). In order to determine whether the DA antagonist modulated the chronic effect of MPD, the MPD locomotor activity at ED12 was compared with that observed at ED11 post-MPD administration of the same group. Figure $2 \mathrm{C}$ shows that acute and chronic MPD exposure elicited a significant $(P<0.006$, $F=10.81$ ) increase in activity. The D1 DA antagonist given at ED12, 30 minutes prior to the last MPD exposure, significantly $(P<0.0006, F=19)$ attenuated the locomotor activity of group 6 (Figure 2C), while the D2 DA antagonist (group 7) reduced the MPD effect but not significantly $(P<0.09, F=0.8)$. Thus, the D2 antagonist was unable to prevent the chronic (sensitization) MPD effect (Figure 2C).

\section{How long a single DA antagonist exerts its effects on MPD exposure between groups} A single D1 and D2 DA antagonist exposure given at ED2 (groups 2 and 3) (Figure 3A and B) or at ED3 (groups 4 and 5) 


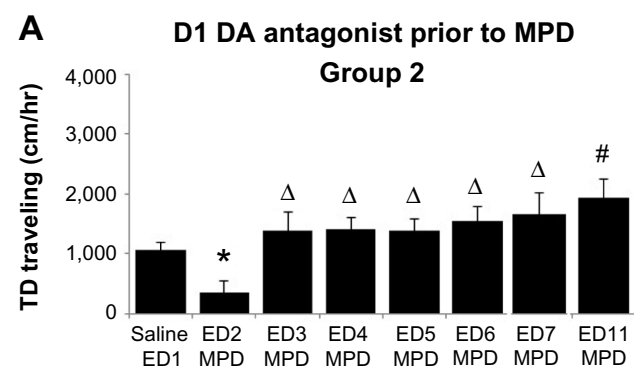

C

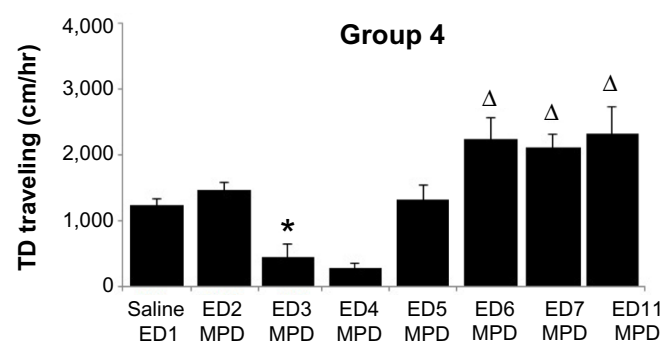

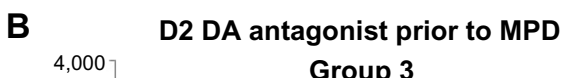

Group 3

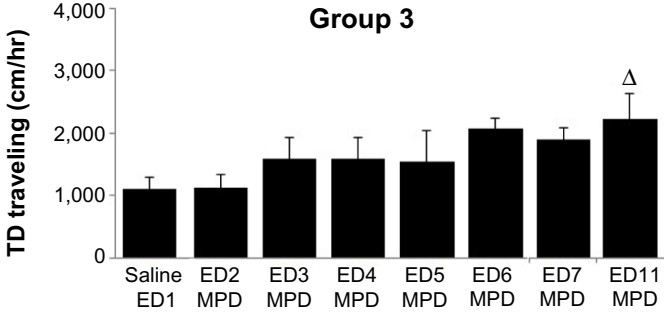

D D1 DA antagonist prior to the 2nd MPD

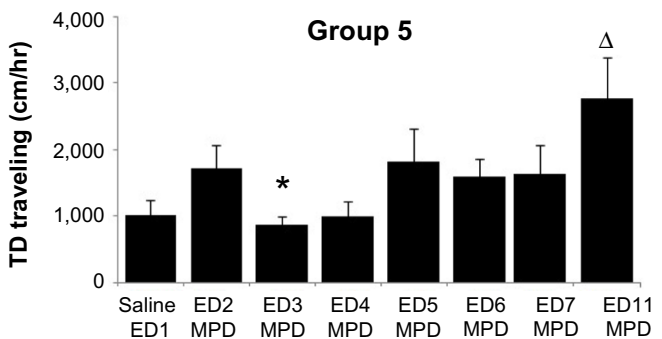

Figure 3 Duration of the DA antagonist effect. The graphs summarize the data to show whether single DA antagonist modulated the MPD effect and for how long: data of (A) group 2 and (B) group 3 that were treated with single DI or D2 DA antagonist prior to the first MPD exposure, respectively; and data of (C) group 4 and (D) group 5 that were treated with single DI or D2 DA antagonist prior to the second MPD exposure.

Notes: The first bar indicates saline at EDI, the second bar indicates locomotor activity following acute MPD exposure in groups 2 and 3 , and the third bar indicates the effect of MPD after DA antagonist treatment in the induction phase. *Significant $(P<0.05)$ from baseline; ${ }^{\Delta}$ significantly different $(P<0.05)$ from MPD control; ${ }^{*}$ significant differences when comparing the activity following the last MPD exposure to the first (behavioral sensitization was expressed).

Abbreviations: DA, dopamine; EDI, experimental day I; MPD, methylphenidate.

were analyzed to determine whether the single DA antagonist effects were transient or long lasting. The attenuation effect of the D1 DA antagonist on MPD induced increases in locomotor activity that lasted for 2 days (Figure 3 ) as compared with their acute MPD response, thus suggesting the D1 and D2 antagonist only exhibited transient, short-term effects.

\section{Discussion}

In the present study, the involvement of DA D1 and D2 receptors in the acute and chronic effect of MPD was investigated. MPD binds to DA transporters and prevents the DA reuptake from the synaptic cleft to the presynaptic terminals that results in an increase in extracellular levels of DA in the synaptic cleft. ${ }^{23,27,49}$ DA mediates the effects of MPD through two groups of receptors: D1 coupled to stimulatory G proteins and D2 coupled to inhibitory G proteins. D1 DA receptors are rapidly recycled, returning to the cell surface for more binding, whereas D2 DA receptors are degraded. ${ }^{50}$ The upregulation of D1 DA receptors via repeated psychostimulant administration is believed to play a key role in the development of behavioral sensitization. ${ }^{51}$ Moreover, it has also been shown that increased D1 DA occupancy results in behavioral sensitization to other psychostimulants, such as cocaine. ${ }^{52}$ There is evidence that DA is a key player in the acute and chronic MPD effect: ${ }^{53}$ however, the exact role of DA D1 or D2 receptors in the effects elicited by MPD is still debated.
The present study endeavored to determine whether blockade of D1 or D2 DA receptors by single treatment of selective DA antagonist given prior to a single (acute) or following repetitive (chronic) MPD exposure would prevent the acute and/or the chronic MPD effects (eg, behavioral sensitization), using the open field assay. The main findings of this study showed the importance of D1 DA receptor for both the acute and chronic MPD effects on locomotion. D1 DA antagonist (SCH-23390) was able to attenuate the MPD locomotor activity given both prior to the acute phase and during the induction and the expression phases (chronic) of MPD effects. The D2 DA antagonist (raclopride) showed a slight attenuation of MPD locomotor activity, only when given in the induction phase. These results implicate the importance of D1 receptors as a direct mechanism involved in the acute and chronic expression of MPD, while the D2 receptors may have a secondary role that remains unclear. Furthermore, a comparison analysis of the MPD response following single exposures to D1 or D2 DA antagonist found all locomotor attenuation to be transient, with the response only lasting about 2 days.

Previous studies using different psychostimulant drugs and different experimental assays are in agreement with the current findings. The D1 DA antagonist SCH-23390 prevented the self-administration of amphetamine and the development of behavioral sensitization to cocaine, whereas 
the D2 antagonist raclopride was less effective. ${ }^{28,54}$ Meririnne et $\mathrm{al}^{19}$ investigated the effects of D1 and D2 antagonist using the place preference assay and reported that DA D1 antagonist was able to prevent the MPD-induced place preference.

Alteration of behavioral sensitization following repetitive administration of MPD, using other drugs, has been reported. ${ }^{33,44,45,55}$ These investigations, using similar experimental protocols of repeated MPD exposure, reported that partial block of MPD elicited behavioral sensitization following injection of valproate, ${ }^{33,44,45,55}$ a gamma-aminobutyric acid (GABA) agonist, and MK-801,37 a specific NMDA antagonist, given at ED2, ED3, and ED12. Yang et $\mathrm{a}^{56}$ studied the effects of lithium chloride on acute and chronic MPD administration, and reported that lithium slightly attenuated the acute effects of MPD; however, no effect of lithium was observed on the development and expression of behavioral sensitization.

It was reported that MPD exposure elicits excitation in neurons belonging to the motive/reward circuit ${ }^{57-63}$ and that the DA D1 antagonist reduced or prevented the MPD effects, ${ }^{46,64,65}$ similar to what was observed in this behavioral study. This suggests that the DA D1 receptors are the main liaison of MPD action, while Andrews and Lavin ${ }^{57}$ reported that in their study, DA D1 receptors did not play a role in MPD action. Volz et $\mathrm{al}^{65}$ reported that the activation of DA D2 receptors are the liaison of MPD action in the striatum, a structure involved in regulating motor activity, suggesting that the DA D2 receptors are the main participants in MPD action.

These results suggest that the development of behavioral sensitization is multifaceted. It is not one specific receptor that participates in the behavioral response to acute and chronic MPD but rather, several receptors synergistically participating in the expression of behavioral sensitization. The results point to the important role of specific D1 receptors in acute and chronic MPD treatment. More specific analysis, using direct injection of DA antagonist into the motive circuit structures, is needed in order to understand the exact role of D1 and D2 DA receptors in the induction and expression of behavioral sensitization. Furthermore, the D3 DA receptor, homologous to the D2 DA receptor, has received interest in recent studies ${ }^{46}$ for its role in drug addiction. Currently, selective D3 antagonists are just being synthesized, and therefore, limited research is available on their direct effects. Most studies show the results of a D2/D3 mixed antagonist effect, although it is hard to postulate whether the seen results are from D2/D3 or even other neurotransmitter receptors. It would be beneficial to use SB-277011-A, a new selective
D3 antagonist, to investigate whether results seen are directly related to D2 DA receptor blockade or D3 receptors. ${ }^{66,67}$

\section{Acknowledgment}

This research was supported in part by a National Institutes of Health (NIH) (grant number R01DA27222) grant.

\section{Disclosure}

The authors report no conflicts of interest in this work.

\section{References}

1. Jensen PS, Hinshaw SP, Swanson JM, et al. Findings from the NIMH Multimodal Treatment Study of ADHD (MTA): implications and applications for primary care providers. J Dev Behav Pediatr. 2001;22(1): 60-73.

2. Shaywitz BA, Fletcher JM, Shaywitz SE. Attention deficit hyperactivity disorder. Curr Treat Options Neurol. 2001;3(3):229-236.

3. Swanson JM, Cantwell D, Lerner M, McBurnett K, Hanna G. Effects of stimulant medication on learning in children with ADHD. J Learn Disabil. 1991;24(4):219-230, 255.

4. Yang PB, Swann AC, Dafny N. Acute and chronic methylphenidate dose-response assessment on three adolescent male rat strains. Brain Res Bull. 2006;71(1-3):301-310.

5. Yang PB, Swann AC, Dafny N. Chronic methylphenidate modulates locomotor activity and sensory evoked responses in the VTA and NAc of freely behaving rats. Neuropharmacology. 2006;51(3):546-556.

6. Yang PB, Swann AC, Dafny N. Dose-response characteristics of methylphenidate on locomotor behavior and on sensory evoked potentials recorded from the VTA, NAc, and PFC in freely behaving rats. Behav Brain Funct. 2006;4:25-36.

7. Yang PB, Swann AC, Dafny N. Sensory-evoked potentials recordings from the ventral tegmental area, nucleus accumbens, prefrontal cortex, and caudate nucleus and locomotor activity are modulated in dose-response characteristics by methylphenidate. Brain Res. 2006;1073-1074: 164-174.

8. Froehlich TE, Lanphear BP, Epstein JN, Barbaresi WJ, Katusic SK, Kahn RS. Prevalence, recognition, and treatment of attention-deficit/ hyperactivity disorder in a national sample of US children. Arch Pediatr Adolesc Med. 2007;161(9):857-864.

9. Mayes R, Bagwell C, Erkulwater J. ADHD and the rise in stimulant use among children. Harv Rev Psychiatry. 2008;16(3):151-166.

10. Stix G. Turbocharging the brain. Sci Am. 2009;301(4):46-49, 52.

11. Nestler EJ. Molecular basis of long-term plasticity underlying addiction. Nat Rev Neurosci. 2001;2(2):119-128.

12. Volkow ND, Ding YS, Fowler JS, et al. A new PET ligand for the dopamine transporter: studies in the human brain. J Nucl Med. 1995;36(12): $2162-2168$.

13. Wilens TE, Biederman J. The stimulants. Psychiatr Clin North Am. 1992;15(1):191-222.

14. Wilens TE, Spencer TJ. The stimulants revisited. Child Adolesc Psychiatr Clin NAm. 2000;9(3):573-603.

15. Wilens TE, Boellner SW, López FA, et al. Varying the wear time of the methylphenidate transdermal system in children with attentiondeficit/hyperactivity disorder. J Am Acad Child Adolesc Psychiatry. 2008;47(6):700-708.

16. Chao J, Nestler EJ. Molecular neurobiology of drug addiction. Annu Rev Med. 2004;55:113-132.

17. Gaytan O, al-Rahim S, Swann A, Dafny N. Sensitization to locomotor effects of methylphenidate in the rat. Life Sci. 1997;61(8): L101-L107.

18. Kalivas PW, Stewart J. Dopamine transmission in the initiation and expression of drug- and stress-induced sensitization of motor activity. Brain Res Brain Res Rev. 1991;16(3):223-244. 
19. Meririnne E, Kankaanpää A, Seppälä T. Rewarding properties of methylphenidate: sensitization by prior exposure to the drug and effects of dopamine D1- and D2-receptor antagonists. J Pharmacol Exp Ther. 2001;298(2):539-550.

20. Teo SK, Stirling DI, Hoberman AM, Christian MS, Thomas SD, Khetani VD. D-methylphenidate and D,L-methylphenidate are not developmental toxicants in rats and rabbits. Birth Defects Res B Dev Reprod Toxicol. 2003;68(2):162-171.

21. Askenasy EP, Taber KH, Yang PB, Dafny N. Methylphenidate (Ritalin): behavioral studies in the rat. Int J Neurosci. 2007;117(6):757-794.

22. Robinson TE, Berridge KC. The neural basis of drug craving: an incentive-sensitization theory of addiction. Brain Res Brain Res Rev. 1993;18(3):247-291.

23. Gatley SJ, Volkow ND, Gifford AN, et al. Dopamine-transporter occupancy after intravenous doses of cocaine and methylphenidate in mice and humans. Psychopharmacology (Berl). 1999;146(1): 93-100.

24. Volkow ND, Fowler JS, Wang GJ. Imaging studies on the role of dopamine in cocaine reinforcement and addiction in humans. $J$ Psychopharmacol. 1999;13(4):337-345.

25. Beyer CE, Steketee JD. Cocaine sensitization: modulation by dopamine D2 receptors. Cereb Cortex. 2002;12(5):526-535.

26. Teo SK, Stirling DI, Hoberman AM, Christian MS, Thomas SD, Khetani VD. D-methylphenidate and D, L-methylphenidate are not developmental toxicants in rats and rabbits. Birth Defects Res B Dev Reprod Toxicol. 2003;68(2):162-171.

27. Kuczenski R, Segal DS. Effects of methylphenidate on extracellular dopamine, serotonin, and norepinephrine: comparison with amphetamine. J Neurochem. 1997;68(5):2032-2037.

28. Shippenberg TS, Heidbreder C. Sensitization to the conditioned rewarding effects of cocaine: pharmacological and temporal characteristics. J Pharmacol Exp Ther. 1995;273(2):808-815.

29. Ujike H, Akiyama K, Otsuki S. D-2 but not D-1 dopamine agonists produce augmented behavioral response in rats after subchronic treatment with methamphetamine or cocaine. Psychopharmacology (Berl). 1990;102(4):459-464

30. Kuribara H, Uchihashi Y. SCH 23390 equivalently, but YM-09151-2 differentially reduces the stimulant effects of methamphetamine, MK-801 and ketamine: assessment by discrete shuttle avoidance in mice. Jpn J Pharmacol. 1993;62(1):111-114.

31. Liu YP, Lin PJ, Tseng CJ, Wan FJ, Tung CS. Role of dopaminergic DAD1 and DAD2 receptors in the sensitization of amphetaminesuppressed schedule-induced polydipsia in rats. Chin J Physiol. 2009;52(5):280-288.

32. Meng ZH, Feldpaush DL, Merchant KM. Clozapine and haloperidol block the induction of behavioral sensitization to amphetamine and associated genomic responses in rats. Brain Res Mol Brain Res. 1998;61(1-2):39-50.

33. Eckermann K, Beasley A, Yang P, Gaytan O, Swann A, Dafny N. Methylphenidate sensitization is modulated by valproate. Life Sci. 2001;69(1):47-57.

34. Gaytan O, Lewis C, Swann A, Dafny N. Diurnal differences in amphetamine sensitization. Eur J Pharmacol. 1999;374(1):1-9.

35. Gaytan O, Yang P, Swann A, Dafny N. Diurnal differences in sensitization to methylphenidate. Brain Res. 2000;864(1):24-39.

36. Gaytan O, Sripada S, Swann A, Dafny N. Blockade of sensitization to methylphenidate by MK-801: partial dissociation from motor effects. Neuropharmacology. 2001;40(2):298-309.

37. Gaytan O, Swann AC, Dafny N. Disruption of sensitization to methylphenidate by a single administration of MK-801. Life Sci. 2002;70(19):2271-2285.

38. Algahim MF, Yang PB, Wilcox VT, Burau KD, Swann AC, Dafny N. Prolonged methylphenidate treatment alters the behavioral diurnal activity pattern of adult male Sprague-Dawley rats. Pharmacol Biochem Behav. 2009;92(1):93-99.

39. Yang PB, Swann AC, Dafny N. Chronic pretreatment with methylphenidate induces cross-sensitization with amphetamine. Life Sci. 2003;73(22):2899-2911.
40. Yang PB, Swann AC, Dafny N. Methylphenidate treated at the test cage - dose-dependent sensitization or tolerance depend on the behavioral assay used. Crit Rev Neurobiol. 2007;19(1):59-77.

41. Yang PB, Atkins KD, Dafny N. Behavioral sensitization and crosssensitization between methylphenidate amphetamine, and 3,4-methylene dioxymethamphetamine (MDMA) in female SD rats. Eur J Pharmacol. 2011;661(1-3):72-85.

42. Chelaru MI, Yang PB, Dafny N. Sex differences in the behavioral response to methylphenidate in three adolescent rat strains (WKY, SHR, SD). Behav Brain Res. 2012;226(1):8-17.

43. Claussen C, Dafny N. Acute and chronic methylphenidate modulates the neuronal activity of the caudate nucleus recorded from freely behaving rats. Brain Res Bull. 2012;87(4-5):387-396.

44. Yang P, Beasley A, Eckermann K, Swann A, Dafny N. Valproate prevents the induction of sensitization to methylphenidate (ritalin) in rats. Brain Res. 2000;887(2):276-284.

45. Yang P, Swann A, Dafny N. NMDA receptor antagonist disrupts acute and chronic effects of methylphenidate. Physiol Behav. 2000;71(1-2): 133-145.

46. Gronier B. In vivo electrophysiological effects of methylphenidate in the prefrontal cortex: involvement of dopamine D1 and alpha 2 adrenergic receptors. Eur Neuropsychopharmacol. 2011;21(2):192-204.

47. Bergheim M, Yang PB, Burau KD, Dafny N. Adolescent rat circadian activity is modulated by psychostimulants. Brain Res. 2012;1431: $35-45$.

48. Lee MJ, Yang PB, Wilcox VT, Burau KD, Swann AC, Dafny N. Repetitive methylphenidate administration modulates the diurnal behavioral activity pattern of adult female SD rats. J Neural Transm. 2011;118(2):285-298.

49. Volkow ND, Chang L, Wang GJ, et al. Association of dopamine transporter reduction with psychomotor impairment in methamphetamine abusers. Am J Psychiatry. 2001;158(3):377-382.

50. Svenningsson P, Greengard P. A master regulator in the brain. The Scientist. October 1, 2006. Available from: http://www.the-scientist. com/?articles.view/articleNo/24381/title/A-Master-Regulator-in-theBrain/. Accessed December 15, 2014.

51. Thompson D, Martini L, Whistler JL. Altered ratio of D1 and D2 dopamine receptors in mouse striatum is associated with behavioral sensitization to cocaine. PLoS One. 2010;9:52-61.

52. Burger LY, Martin-Iverson MT. Increased occupation of D1 and D2 dopamine receptors accompanies cocaine-induced behavioral sensitization. Brain Res. 1994;639(2):228-232.

53. Volkow ND, Swanson JM. Variables that affect the clinical use and abuse of methylphenidate in the treatment of ADHD. Am J Psychiatry. 2003;160(11):1909-1918.

54. Pierre PJ, Vezina P. D1 dopamine receptor blockade prevents the facilitation of amphetamine self-administration induced by prior exposure to the drug. Psychopharmacology (Berl). 1998;138(2):159-166.

55. Yang PB, Swann AC, Dafny N. Valproate prevents the induction and the expression of MK-801 sensitization. Brain Res. 2002;954(2): 151-159.

56. Yang P, Singhal N, Modi G, Swann A, Dafny N. Effects of lithium chloride on induction and expression of methylphenidate sensitization. Eur J Pharmacol. 2001;426(1-2):65-72.

57. Andrews GD, Lavin A. Methylphenidate increases cortical excitability via activation of alpha-2 noradrenergic receptors. Neuropsychopharmacology. 2006;31(3):594-601.

58. Claussen CM, Dafny N. Acute administration of methylphenidate alters the prefrontal cortex neuronal activity in a dose-response characteristic. J Exp Pharmacol. 2014;6:1-9.

59. Claussen CM, Chong SL, Dafny N. Nucleus accumbens neuronal activity correlates to the animal's behavioral response to acute and chronic methylphenidate. Physiol Behav. 2014;129:85-94.

60. Jones Z, Dafny N. Dose response effect of methylphenidate on ventral tegmental area neurons and animal behavior. Brain Res Bull. 2013;96: $86-92$.

61. Tang B, Dafny N. Methylphenidate modulates the locus ceruleus neuronal activity in freely behaving rat. Eur J Pharmacol. 2012;695(1-3): $48-56$. 
62. Tang B, Dafny N. Behavioral and dorsal raphe neuronal activity following acute and chronic methylphenidate in freely behaving rats. Brain Res Bull. 2013;98:53-63.

63. Cummins ED, Griffin SB, Duty CM, Peterson DJ, Burgess KC, Brown RW. The role of dopamine $\mathrm{D}_{1}$ and $\mathrm{D}_{2}$ receptors in adolescent methylphenidate conditioned place preference: sex differences and brainderived neurotrophic factor. Dev Neurosci. 2014;36(3-4):277-286.

64. Gamo NJ, Wang M, Arnsten AF. Methylphenidate and atomoxetine enhance prefrontal function through $\alpha 2$-adrenergic and dopamine D1 receptors. J Am Acad Child Adolesc Psychiatry. 2010;49(10): 1011-1023.
65. Volz TJ, Farnsworth SJ, Rowley SD, Hanson GR, Fleckenstein AE. Methylphenidate-induced increases in vesicular dopamine sequestration and dopamine release in the striatum: the role of muscarinic and dopamine D2 receptors. J Pharmacol Exp Ther. 2008;327(1):161-167.

66. Barth V, Need AB, Tzavara ET, et al. In vivo occupancy of dopamine D3 receptors by antagonists produces neurochemical and behavioral effects of potential relevance to attention-deficit-hyperactivity disorder. J Pharmacol Exp Ther. 2013;344(2):501-510.

67. Heidbreder CA, Gardner EL, Xi ZX, et al. The role of central dopamine D3 receptors in drug addiction: a review of pharmacological evidence. Brain Res Brain Res Rev. 2005;49(1):77-105.

\section{Publish your work in this journal}

The Journal of Experimental Pharmacology is an international, peerreviewed, open access journal publishing original research, reports, reviews and commentaries on all areas of laboratory and experimental pharmacology. The manuscript management system is completely online and includes a very quick and fair peer-review system.
Visit http://www.dovepress.com/testimonials.php to read real quotes from published authors. 